\title{
Improving performance of thermally activated delayed fluorescence emitter by extending its LUMO distribution
}

\author{
$\mathrm{Ke} \mathrm{Ke}^{1,2}$, Jia-Xiong Chen ${ }^{2}$, Ming Zhang ${ }^{1,2}$, Kai Wang ${ }^{2 *}$, Yi-Zhong Shi ${ }^{2}$, Hui Lin ${ }^{1}$, Cai-Jun Zheng ${ }^{1^{*}}$, \\ Si-Lu Tao ${ }^{1}$ and Xiao-Hong Zhang ${ }^{2 *}$
}

\begin{abstract}
An optimized compound 9-(9,9-dimethylacridin-10(9H)-yl)-6H-benzo[c]ch-romen-6-one (MAB) was designed and synthesized based on our previously reported TADF emitter 6-(9,9-dimethylacridin-10(9H)-yl)-3-methyl1H-isochromen-1-one (MAC) to further improve the performance of thermally activated delayed fluorescence (TADF) emitters. With the additional phenyl in coumarin-contained plane, MAB possesses an extended distribution of the lowest unoccupied molecular orbitals (LUMO), and thus realizes reduced electron exchange between the frontier molecular orbitals and a stretched molecular dipole moment compared with MAC. MAB based organic light-emitting diode (OLED) exhibits a remarkable maximum external quantum efficiency (EQE) of $21.7 \%$, which is much better than the maximum EQE of MAC-based OLED with a value of $12.8 \%$. Our work proves that extending the distribution of LUMO is a simple but effective method to improve the efficiency of TADF emitter.
\end{abstract}

Keywords: organic light-emitting diode, thermally activated delayed fluorescence, lumo distribution, external quantum efficiency

\section{INTRODUCTION}

Organic light-emitting diodes (OLEDs) have great potential in lighting and display application due to their advantages of low-cost processing, flexibility, and large area production [1-6]. According to spin statistics, electro-excitation produces singlet and triplet excitons with a ratio of 1:3 [7-9]. Initial OLEDs based on traditional fluorescent emitters can only use singlet excitons for emission, leading to a low maximum internal quantum efficiency of 25\% [9-10]. Phosphorescent
OLEDs based on noble metal complexes can achieve $100 \%$ internal quantum efficiency due to the spin-orbit coupling effect of heavy atoms [11-13], but noble metals such as iridium or platinum also increase the manufacturing costs and environmental hazards, causing great concerns [14-16]. Thus, since Adachi and co-workers firstly introduced thermally activated delayed fluorescence (TADF) mechanism into OLEDs [17], a large number of TADF materials have been constructed and reported to realize remarkable device performance [1821]. And TADF-based OLEDs are recognized as the future of OLED technology due to their potential to realize theoretically $100 \%$ internal quantum efficiency with pure organic materials [22-26].

TADF emitters are the fluorophors with extremely small energy splittings $\left(\Delta E_{\mathrm{ST}}\right)$ between the lowest singlet excited state $\left(S_{1}\right)$ and the lowest triplet excited state $\left(T_{1}\right)$, and thus they can enable efficient reverse intersystem crossing (RISC) process from $T_{1}$ to $S_{1}$ and utilize both singlet and triplet excitons for light emission [27,28]. Till now, the general design strategy for TADF emitters is connecting the electron-donor (D) and electron-acceptor (A) segments via a highly twisted structure to constrain the highest occupied molecular orbitals (HOMO) and lowest unoccupied molecular orbitals (LUMO) on D and A segments [29], respectively, which is essential to achieve an extremely small $\Delta E_{\mathrm{ST}}$ [30-34]. Based on such $\mathrm{D}-\mathrm{A}$ structure, a large number of TADF emitters have been successfully developed and realized remarkable external quantum efficiencies (EQEs) even exceeding 20\% [35-38]. However, there are still TADF emitters realizing unsatisfactory efficiencies in the devices,

\footnotetext{
${ }^{1}$ School of Optoelectronic Science and Engineering, University of Electronic Science and Technology of China, Chengdu 610054, China

${ }^{2}$ Functional Nano and Soft Materials Laboratory (FUNSOM) and Collaborative Innovation Center of Suzhou Nano Science and Technology, Soochow University, Suzhou 215123, China

* Corresponding authors (emails: zhengcaijun@uestc.edu.cn (Zheng CJ); xhzhang@mail.ipc.ac.cn (Zhang XH); wkai@suda.edu.cn (Wang K))
} 
although they also possess small $\Delta E_{\mathrm{ST}}$ with highly twisted D-A structures. For example, our group once reported a TADF emitter 6-(9,9-dimethylacridin-10(9H)-yl)-3methyl-1H-isochromen-1-one (MAC) [39]. It successfully exhibits a small $\Delta E_{\mathrm{ST}}$ of $0.157 \mathrm{eV}$ as well as remarkable RISC process; however, the MAC-based OLED only realizes disappointing efficiencies. These unsatisfactory TADF emitters suggest beyond the general highly twisted D-A structure, further optimization on molecular structure is still required. To construct TADF emitters with both small $\Delta E_{\mathrm{ST}}$ and high PLQY value, Adachi and co-workers proposed a strategy by extending the HOMO distributions and realized remarkable performance [27]. However, it should be noted that besides the HOMO distributions, the LUMO distributions should also play an important role in performance of TADF emitters.

In this work, we designed and synthesized an optimized TADF emitter 9-(9,9-dimethylacridin-10(9H)-yl)-6Hbenzo[c]chromen-6-one (MAB) based on MAC. As shown in Fig. 1, MAC and MAB are constructed with similar structures, except methylcoumarin in MAC is replaced by benzocoumarin in MAB. The additional phenyl in coumarin-contained plane will participate in the conjugation of the A segment, resulting in an extended LUMO distribution of MAB. Such extended LUMO would not only decrease the electron density of LUMO and reduce the electron exchange between HOMO and LUMO, but also stretch the transition dipole moment and increase the oscillator strength of the D-A structure molecule, resulting in a smaller $\Delta E_{\mathrm{ST}}$ and enhanced radiative decay [27]. As we expected, $M A B$ successfully realizes an extremely small $\Delta E_{\mathrm{ST}}$ of $0.081 \mathrm{eV}$ and a high photoluminescence quantum yield (PLQY) of $67.9 \%$, which are both much superior to that of MAC $(0.157 \mathrm{eV}$ and $41.8 \%)$. Moreover, in the devices, MAB shows much better performance with a maximum EQE of $21.7 \%$ as well as a maximum current efficiency (CE) of $56.2 \mathrm{~cd} \mathrm{~A}^{-1}$ and a power efficiency (PE) of $53.5 \mathrm{~lm} \mathrm{~W}^{-1}$ compared with MAC (a maximum EQE of $12.8 \%$, a maximum $\mathrm{CE}$ of $28.4 \mathrm{~cd} \mathrm{~A}^{-1}$ and a maximum $\mathrm{PE}$ of $25.5 \mathrm{~lm} \mathrm{~W} \mathrm{~m}^{-1}$ ). These results prove that extending the LUMO distribution is a feasible approach to improve the performance of TADF emitters.

\section{EXPERIMENTAL SECTION}

\section{General methods}

All compounds were synthesized according to the reported procedures. The ${ }^{1} \mathrm{H}$ nuclear magnetic resonance (NMR) and ${ }^{13} \mathrm{C}$ NMR spectra were recorded using an
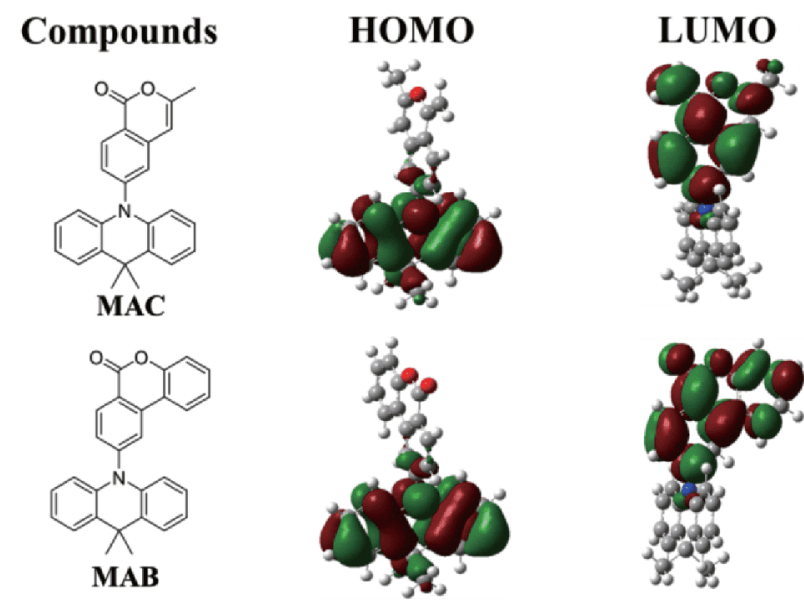

Figure 1 Molecular structures and calculated HOMO and LUMO distributions of MAC and MAB.

AVANCZ spectrometer at $298 \mathrm{~K}$. Mass spectral (MS) data were measured using a Finnigan 4021C gas chromatography mass spectrometry instrument. Elemental analysis (C, H, N) was carried out with an Elementar Vario ELIII element analyzer. UV-vis absorption spectra were measured in toluene using a Shimadzu UV-2700 spectrophotometer at room temperature. Fluorescence and phosphorescence spectra were measured with a Hitachi F-4600 fluorescence spectrophotometer. The transient photoluminescence (PL) decay characteristics were measured with an Edinburgh Instruments FLS980 spectrometer. Cyclic voltammetry $(\mathrm{CV})$ measurements were measured with a CHI660E electrochemical analyzer. Thermal gravimetric analysis (TGA) and differential scanning calorimetry (DSC) were performed using a TAQ 500 thermogravimeter and a NETZSCH DSC204 instrument in $\mathrm{N}_{2}$, respectively. Density functional theory (DFT) calculations were performed using the Gaussian 09 program package. And the PLQYs were estimated at ambient atmosphere via F-3018 integrating sphere.

Synthesis of 5-bromo-(1,1'-biphenyl)-2-carboxylic acid (B) A mixture of 4-bromo-2-iodobenzoic acid (4.9 g, $15 \mathrm{mmol})$, phenylboronic acid $(2.01 \mathrm{~g}, 16.5 \mathrm{mmol})$, lithium hydroxide $(0.718 \mathrm{~g}, 30 \mathrm{mmol})$ and palladium acetate $(33.6 \mathrm{mg}, 0.15 \mathrm{mmol}$ ) were added into a clean $250 \mathrm{~mL}$ flask. The mixed solvent (NMP: $50 \mathrm{~mL}$ and $\mathrm{H}_{2} \mathrm{O}$ : $50 \mathrm{~mL}$ ) was infused into the flask under argon atmosphere rigorously, and then refluxed at $65^{\circ} \mathrm{C}$ for $18 \mathrm{~h}$. After completion of the reaction, the mixture was subjected to an acidic aqueous solution, and then extracted with methyl $t$-butyl ether. The organic phase was dried by anhydrous sodium sulfate and then distilled 


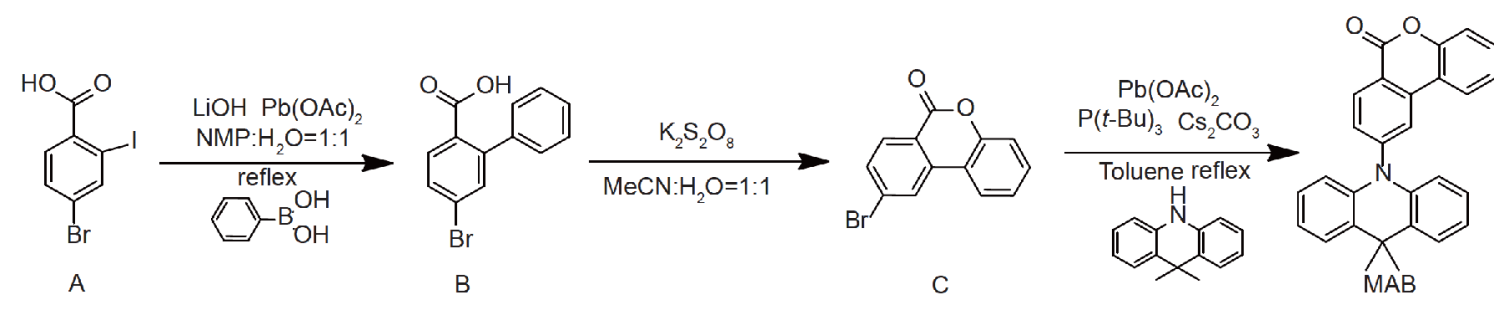

Scheme 1 Synthetic route and molecular structure of MAB.

off. The product was purified by column chromatography with petroleum ether to obtain a pure white powder (2.9 g, 69.7\% yield); ${ }^{1} \mathrm{H}$ NMR (400 MHz, DMSO-d6) $\delta$ $12.82(\mathrm{~s}, 1 \mathrm{H}), 7.86-7.72(\mathrm{~m}, 2 \mathrm{H}), 7.69-7.55(\mathrm{~m}, 1 \mathrm{H}), 7.50$ (dd, $J=10.2$ and $4.7 \mathrm{~Hz}, 1 \mathrm{H}), 7.45-7.33(\mathrm{~m}, 4 \mathrm{H})$. MS (EI) $m / z$ : calcd for $\mathrm{C}_{13} \mathrm{H}_{9} \mathrm{BrO}_{2}\left([\mathrm{M}]^{+}\right)$, 275.98; found: 276.06 .

\section{Synthesis of 9-bromo-benzo[c]chromen-6-one (C)}

The product $\mathrm{B}(2.9 \mathrm{~g}, 10.4 \mathrm{mmol})$ was added to the reaction flask with mixed solvent $(\mathrm{MeCN}: 50 \mathrm{ml}$ and $\left.\mathrm{H}_{2} \mathrm{O}: 50 \mathrm{ml}\right)$ and $\mathrm{K}_{2} \mathrm{~S}_{2} \mathrm{O}_{8}(7.1 \mathrm{~g}, 26.2 \mathrm{mmol})$. The mixture was refluxed at $65^{\circ} \mathrm{C}$ for $18 \mathrm{~h}$. After the reaction, the mixture was cooled to room temperature and added $100 \mathrm{ml}$ saturated $\mathrm{NaHCO}_{3}$ solution. Then the mixture was extracted with ethyl acetate. The organic solvent was dried by rotary evaporation and purified by column chromatography to obtain the product $(1.4 \mathrm{~g}, 48.6 \%$ yield). ${ }^{1} \mathrm{H}$ NMR (400 MHz, DMSO- $\left.d 6\right) \quad \delta 8.73$ (d, $J$ $=1.8 \mathrm{~Hz}, 1 \mathrm{H}), 8.46(\mathrm{dd}, J=8.0$ and $1.4 \mathrm{~Hz}, 1 \mathrm{H}), 8.16(\mathrm{~d}, J=$ $8.5 \mathrm{~Hz}, 1 \mathrm{H}), 7.88(\mathrm{dd}, J=8.5$ and $1.8 \mathrm{~Hz}, 1 \mathrm{H}), 7.61(\mathrm{dd}$, $J=7.1$ and $1.3 \mathrm{~Hz}, 1 \mathrm{H}$ ), 7.43 (ddd, $J=11.9,6.7$, and $2.6 \mathrm{~Hz}$, $2 \mathrm{H})$. MS (EI) $m / z$ : calcd. for $\mathrm{C}_{13} \mathrm{H}_{7} \mathrm{BrO}_{2}\left([\mathrm{M}]^{+}\right), 273.96$; found, 274.09 .

\section{Synthesis of 9-(9,9-dimethylacridin-10(9H)-yl)-6H-benz-o [c]chromen-6-one (MAB)}

The product C (1.1 g, $4 \mathrm{mmol})$, 9,9-dimethyl-9,10dihydroacridine (DMAC) $(920 \mathrm{mg}, 4.4 \mathrm{mmol})$, palladium acetate $(26.9 \mathrm{mg}, 0.12 \mathrm{mmol})$ and cesium carbonate $(3.91 \mathrm{~g}, 12 \mathrm{mmol}$ ) were added to a $100 \mathrm{ml}$ reaction flask, and then $30 \mathrm{ml}$ toluene solvent and tri-t-butylphosphine $(0.47 \mathrm{ml}, 0.2 \mathrm{mmol})$ were added. The mixture was refluxed at $110^{\circ} \mathrm{C}$ for $24 \mathrm{~h}$ under argon atmosphere. After cooling to room temperature, the organic phase was extracted between water and methylene chloride solution, then dried over anhydrous sodium sulfate, evaporated, and purified by column chromatography to give the desired compound 9-(9,9-dimethylacridin-10(9H)-yl)$6 \mathrm{H}$-benzo[c]chromen-6-one as a green solid $(1.04 \mathrm{~g}$, $64.6 \%$ yield). ${ }^{1} \mathrm{H}$ NMR $\left(400 \mathrm{MHz}, \mathrm{CDCl}_{3}\right) \delta 8.64(\mathrm{~d}, J$ $=8.4 \mathrm{~Hz}, 1 \mathrm{H}), 8.12(\mathrm{~d}, J=1.7 \mathrm{~Hz}, 1 \mathrm{H}), 7.96(\mathrm{dd}, J=8.0$,
$1.3 \mathrm{~Hz}, 1 \mathrm{H}), 7.60-7.48(\mathrm{~m}, 4 \mathrm{H}), 7.42(\mathrm{dd}, J=8.3,1.1 \mathrm{~Hz}$, $1 \mathrm{H}), 7.35-7.28(\mathrm{~m}, 1 \mathrm{H}), 7.05-6.98(\mathrm{~m}, 4 \mathrm{H}), 6.43-6.37(\mathrm{~m}$, $2 \mathrm{H}), 1.72(\mathrm{~s}, 6 \mathrm{H}) .{ }^{13} \mathrm{C}$ NMR $\left(101 \mathrm{MHz}, \mathrm{CDCl}_{3}\right) \delta 151.54$, $148.17,140.21,137.70,133.67,131.67,131.06,130.51$, $126.56,125.57,124.71,123.11,122.93,121.76,120.14$, $117.95,117.62,115.08,77.24,36.29,31.06$. MS (EI) $\mathrm{m} / z$ : calcd. for $\mathrm{C}_{28} \mathrm{H}_{21} \mathrm{NO}_{2}\left([\mathrm{M}]^{+}\right), 403.16$; found, 403.53. Anal. calcd. for $\mathrm{C}_{28} \mathrm{H}_{21} \mathrm{NO}_{2}$ (\%): C, 83.37; $\mathrm{H}, 5.19 ; \mathrm{N}, 3.52 ; \mathrm{O}$, 7.92. Found: C, 83.29; H, 5.23; N, 3.49, O, 7.99.

\section{Device fabrication and measurements}

All devices were prepared with the vacuum thermal evaporation process. Before making the devices, the indium-tin oxide (ITO) glass substrates ( $15 \Omega$ per square) were carefully cleaned in an ultrasonic bath with detergent, ethyl alcohol and deionized water in sequence, then dried in an oven at $120^{\circ} \mathrm{C}$ over $2 \mathrm{~h}$. Followed, the substrates were treated with ultraviolet-ozone for $30 \mathrm{~min}$. Then, the processed glass substrates were transferred to a vacuum deposition system under a pressure less than $5 \times$ $10^{-4} \mathrm{~Pa}$. Organic layers, $\mathrm{LiF}$ and $\mathrm{Al}$ were sequentially evaporated on ITO with the rates of 2, 0.1 and $10 \AA \mathrm{s}^{-1}$, respectively. The EL spectra, CIE coordinates and luminance of the devices were measured with a Spectrascan PR655 photometer and the current-voltage characteristics were determined using a Keithley 2400 Source Meter under ambient atmosphere. The EQE values were calculated from the current density, luminance, and EL spectrum, assuming a Lambertian distribution.

\section{RESULTS AND DISCUSSION}

\section{Synthesis}

The synthetic route of MAB is shown in Scheme 1. A benzene ring firstly substituted the iodine atom on 2iodo-4-bromobenzoic acid (A) via the Suzuki reaction. Then the resulting product 5-bromo-(1,1'-biphenyl)-2carboxylic acid (B) was self-cyclized to form 9-bromobenzo[c]chromen-6-one (C) [40]. The target product MAB was finally obtained via a palladium-catalyzed 
Buchwald-Hartwig coupling between C and DMAC. And MAC was synthesized according to the route reported in our previous work [39]. The products obtained in each step were verified by MS and NMR spectroscopy. And both MAB and MAC were further purified by sublimation before further characterizations.

\section{Theoretical calculations and electrochemical measurement} We first performed DFT calculation on two coumarin derivatives at the B3LYP/6-31G(d) level to analyze their properties at molecular level. As shown in Fig. 1, both compounds exhibit similar highly twisted structures, and the dihedrals between $\mathrm{D}$ and $\mathrm{A}$ segments are estimated to be $89.96^{\circ}$ and $89.03^{\circ}$ for $\mathrm{MAB}$ and MAC, respectively, which will promote the separation between the frontier molecular orbitals. The HOMOs are mainly confined on DMAC segments, and the LUMOs are mainly located on the coumarin-contained planes. With the additional phenyl, MAB possesses an extended LUMO distribution compared with MAC. Obviously, there are only slight overlaps between HOMO and LUMO for both compounds. Thus, MAC and MAB have the potential to realize extremely small $\Delta E_{\mathrm{ST}}$. And the $\Delta E_{\mathrm{ST}}$ of MAC and $\mathrm{MAB}$ are theoretically predicted to be small values of 0.01 and $0.0089 \mathrm{eV}$, respectively, which would guarantee both two compounds exhibit TADF characteristic. Meanwhile, the theoretical $\triangle E_{\mathrm{ST}}$ of MAB is smaller than that of MAC. This difference is because the extended LUMO distribution of MAB will further disperse the electron density and reduce the electron exchange between HOMO and LUMO. Moreover, the conjugation-extended benzocoumarin in MAB is also helpful to stretch dipole moment and increase the oscillator strength. In MAB, the transition dipole moment from $S_{0}$ to $S_{1}$ is $0.0009 \mathrm{D}$ and the oscillator strength is $3.55 \times 10^{-7}$, while the transition dipole moment from $S_{0}$ to $S_{1}$ of MAC is $0.0005 \mathrm{D}$ with oscillator strength of $2.38 \times 10^{-7}$. Obviously, the transition dipole moment and the oscillator strength of $\mathrm{MAB}$ are evidently larger than that of MAC, which would benefit the fluorescence process.

$\mathrm{CV}$ measurements were then carried out to characterize the electrochemical properties of the two compounds. As shown in Fig. 2, from the onsets of oxidation curves, the HOMO energy levels are calculated to be similar values of $-5.56 \mathrm{eV}$ for MAC and $-5.58 \mathrm{eV}$ for MAB, respectively, which should be ascribed to their identical D segment of DMAC. Meanwhile, from the onsets of reduction curves, the LUMO energy level of MAB is calculated to be $-2.93 \mathrm{eV}$, and MAC exhibits a slightly higher LUMO energy level of $-2.81 \mathrm{eV}$. The lower LUMO energy level of
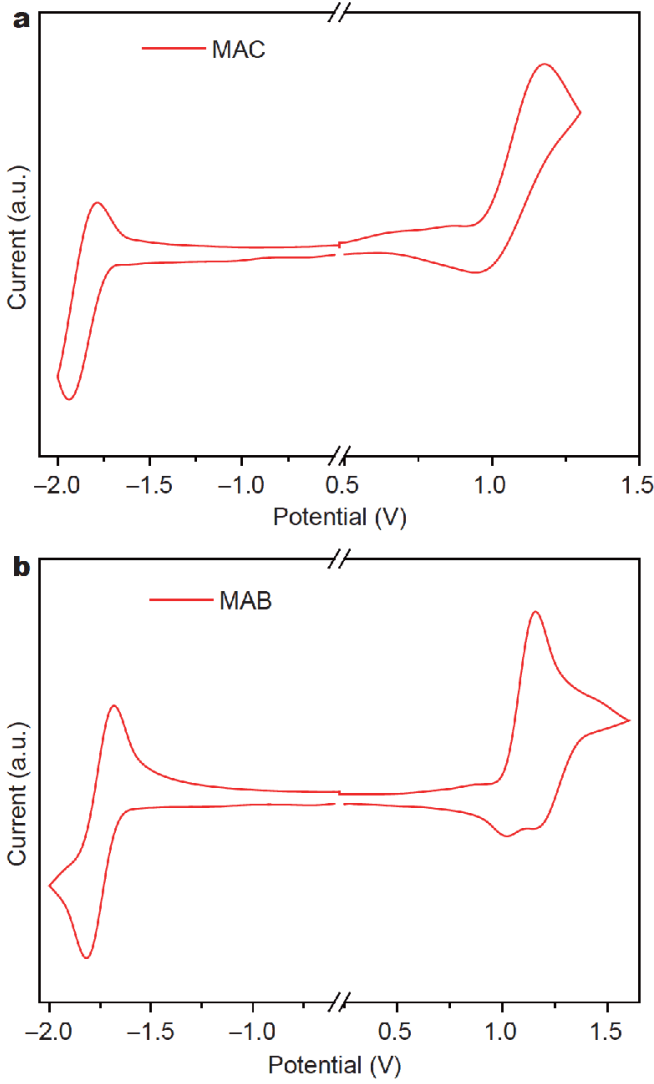

Figure 2 Cyclic voltammetry measurements of (a) MAC and (b) MAB in DMF.

MAB is caused by the extended conjugation of the additional phenyl groups.

\section{Photophysical properties}

UV-vis absorption spectra of MAC and MAB were measured in dilute toluene solution at room temperature. As shown in Fig. 3, due to their similar components, both two compounds exhibit nearly identical absorption profiles. The absorption below $370 \mathrm{~nm}$ should be attributed to the local excited transitions of D and A segments. While the absorption band in the region from 370 to $425 \mathrm{~nm}$ should be ascribed to the intramolecular charge transfer (ICT) transition from the electrondonating DMAC group to the electron-withdrawing coumarin segment. Specifically, with the extended conjugation, the absorption edge of MAB $(428 \mathrm{~nm})$ is slightly red-shifted compared with that of MAC $(419 \mathrm{~nm})$. And the optical band gaps are accordingly estimated to be $2.90 \mathrm{eV}$ for $\mathrm{MAB}$ and $2.96 \mathrm{eV}$ for MAC, respectively, which are mainly induced by the lower LUMO energy level of MAB. To further prove the ICT characteristics of two compounds, we measured their PL 

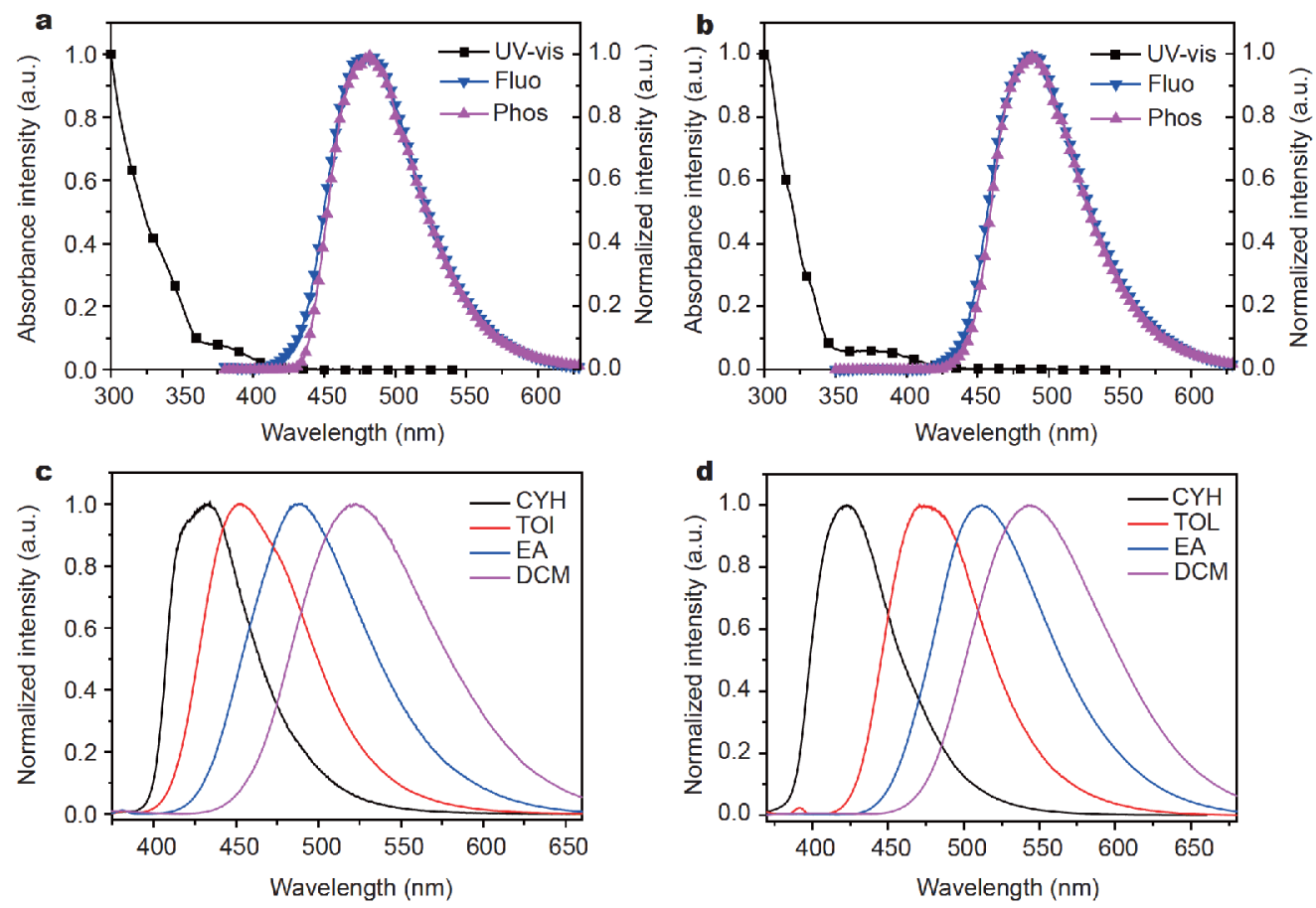

Figure 3 UV-vis absorption in dilute toluene solution at room temperature and fluorescence and phosphorescence in DPEPO thin solid film at $77 \mathrm{~K}$ of (a) MAC and (b) MAB; fluorescence spectra of (c) MAC and (d) MAB in different solvents at room temperature.

spectra in different solvents. As shown in Fig. $3 \mathrm{c}$ and $\mathrm{d}$, with gradually increased solvent polarity from non-polar cyclohexane to higher polar toluene, ethyl acetate, and dichloromethane, significant solvatochromic effect can be observed for both compounds. The emission peak is redshifted from $434 \mathrm{~nm}$ in cyclohexane to $522 \mathrm{~nm}$ in dichloromethane with an entire shift of $88 \mathrm{~nm}$ for MAC. While for MAB, the emission peaks are 422 and $542 \mathrm{~nm}$ in cyclohexane and dichloromethane, respectively; and the entire red-shift is $120 \mathrm{~nm}$. The higher Stokes shift of MAB is well consistent with its higher dipole moment than MAC.

The fluorescence and phosphorescence spectra of $14 \mathrm{wt} \%$ MAC and $20 \mathrm{wt} \%$ MAB doped bis(2-(diphenylphosphino)phenyl)ether oxide (DPEPO) films were respectively measured at $77 \mathrm{~K}$. From the onsets of fluorescence and phosphorescence spectra, the $S_{1}$ and $T_{1}$ energy levels are estimated to be 3.054 and $2.897 \mathrm{eV}$ for $\mathrm{MAC}$ and 2.997 and $2.916 \mathrm{eV}$ for $\mathrm{MAB}$, respectively. Thus, the $\Delta E_{\mathrm{ST}}$ is calculated to be $0.157 \mathrm{eV}$ for MAC and $0.081 \mathrm{eV}$ for $\mathrm{MAB}$, respectively. Such small $\Delta E_{\mathrm{ST}}$ can benefit the RISC process and lead TADF characteristic to both two compounds. Compared with MAC, MAB exhibits an evidently smaller $\Delta E_{\mathrm{ST}}$, which is consistent with our theoretical prediction and would be more helpful to the utilization of triplet excitons. To prove the
TADF behaviors of MAC and MAB, we also measured the transient PL decay curves of two doped films. Both the emitters exhibit the prompt and delayed components. At room temperature, the prompt and delayed decay lifetimes of MAC are $6.4 \mathrm{~ns}$ and $15.6 \mu \mathrm{s}$, respectively; and MAB shows a transient lifetime of $9.4 \mathrm{~ns}$ and a delayed decay lifetime of $10.5 \mu$ s. Moreover, as shown in Fig. 4, with the temperature gradually increased from 100 to $300 \mathrm{~K}$, the delayed decays of both compounds become evidently faster, confirming MAC and MAB are TADF emitters. In addition, we further measured the PLQYs of $14 \mathrm{wt} \%$ MAC and $20 \mathrm{wt} \%$ MAB doped DPEPO films under atmosphere. As summarized in Table 1, the PLQY values of MAC and MAB are estimated to be $41.8 \%$ and $67.9 \%$, respectively. Accordingly, we obtained the prompt and delayed fluorescence quantum yields of MAB is $9.2 \%$ and $58.7 \%$, respectively, and the MAC of $12.3 \%$ and $29.5 \%$. It can be seen that the delayed partial fluorescence quantum yield of $M A B$ is higher than that of MAC, proving that $\mathrm{MAB}$ has superior TADF behavior. And the higher PLQY of MAB is also consistent with our prediction, which should be promoted by its smaller $\Delta E_{\mathrm{ST}}$ and stretched molecular dipole moment. Although part of triplet excitons would be quenched by oxygen in atmosphere, significantly higher PLQY of MAB also indicates its better exciton utilization with the extended 

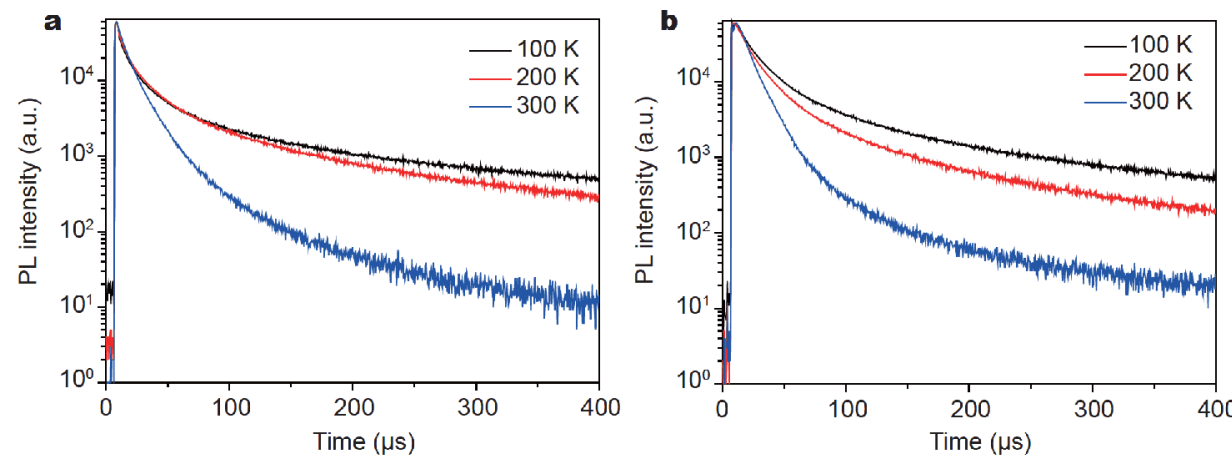

Figure 4 Transient PL decay curves of (a) 14 wt $\%$ MAC and (b) 20 wt\% MAB doped DPEPO films at different temperatures.

Table 1 Key physical properties of MAC and MAB

\begin{tabular}{cccccccccc}
\hline & $\begin{array}{c}\lambda_{\text {abs }} \\
(\mathrm{nm})^{\mathrm{a}}\end{array}$ & $\begin{array}{c}\lambda_{\mathrm{em}} \\
(\mathrm{nm})^{\mathrm{a}}\end{array}$ & $\begin{array}{c}\text { HOMO/LUMO } \\
(\mathrm{eV})^{\mathrm{b}}\end{array}$ & $\begin{array}{c}S_{1} \\
(\mathrm{eV})^{\mathrm{c}}\end{array}$ & $\begin{array}{c}T_{1} \\
(\mathrm{eV})^{\mathrm{c}}\end{array}$ & $\begin{array}{c}\Delta E_{\text {ST }} \\
(\mathrm{eV})\end{array}$ & $\begin{array}{c}T_{\mathrm{d}} \\
\left({ }^{\circ} \mathrm{C}\right)\end{array}$ & $\begin{array}{c}T_{\mathrm{g}} \\
\left({ }^{\circ} \mathrm{C}\right)\end{array}$ & $\begin{array}{c}\text { PLQY } \\
\text { MAC }\end{array}$ \\
\hline 33 & 452 & $-5.56 /-2.81$ & 3.054 & 2.897 & 0.157 & 293 & 56 & $41.8 \%$ \\
MAB & 374 & 470 & $-5.58 /-2.93$ & 2.997 & 2.916 & 0.081 & 367 & 78 & $67.9 \%$ \\
\hline
\end{tabular}

a) Measured in dilute toluene at room temperature. b) Determined from the oxidation and reduction potential in a $10^{-3}$ mol L $\mathrm{L}^{-1} \mathrm{DMF}$ solution by CV.c) Determined from the onsets of the fluorescence and phosphorescence spectra in DPEPO film at $77 \mathrm{~K}$.

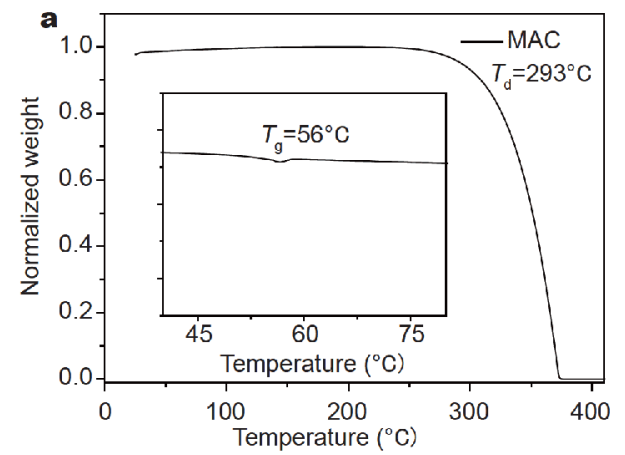

Figure 5 TGA and DSC (inset) measurement of (a) MAC, and (b) MAB.

\section{Thermal properties}

The thermal properties of MAC and $\mathrm{MAB}$ were investigated by TGA and DSC measurements under nitrogen atmosphere. As presented in Fig. 5, the decomposition temperatures ( $T_{\mathrm{d}}$ with $5 \%$ weight loss) of MAC and $\mathrm{MAB}$ are 293 and $367^{\circ} \mathrm{C}$, and the glass transition temperatures $\left(T_{\mathrm{g}}\right)$ are 56 and $78^{\circ} \mathrm{C}$, respectively. Obviously, with the additional phenyl, MAB shows much better thermal stability than MAC, more suitable for device application.

\section{Morphological characteristics}

To study the morphological stability of two compounds,

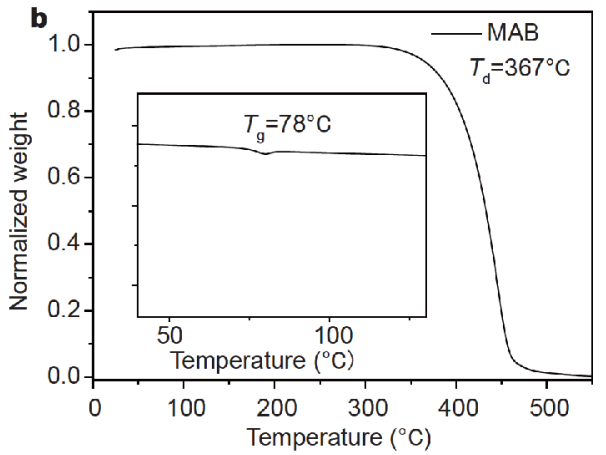

we used atomic force microscopy (AFM) to explore surface images of vacuum evaporation-processed films of $20 \mathrm{wt} \% \mathrm{MAB}$ and $14 \mathrm{wt} \%$ MAC doped into DPEPO host. As shown in Fig. 6, two doped films exhibit smooth surfaces without pinhole, and the root mean square roughness is $0.315 \mathrm{~nm}$ for MAC and $0.332 \mathrm{~nm}$ for $\mathrm{MAB}$, respectively. These evidences indicate that two emitters can form very smooth and amorphous films via vacuum evaporation process.

\section{Electroluminescence properties}

To characterize the electroluminescence (EL) properties of MAC and MAB, the OLEDs using them as the emitters were fabricated with the device structure of ITO/TAPC $(35 \mathrm{~nm}) / \mathrm{TCTA}(10 \mathrm{~nm}) / \mathrm{CzSi}(10 \mathrm{~nm}) / \mathrm{DPEPO}:(x \mathrm{wt} \%)$ 

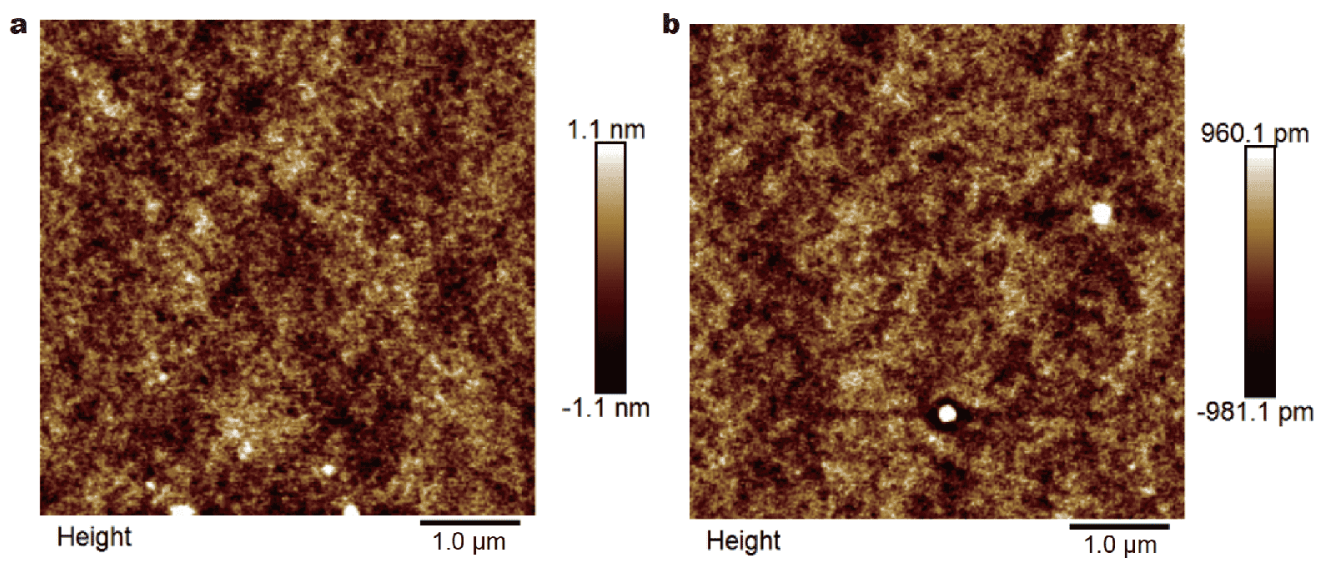

Figure 6 The AFM images of the vacuum evaporation process (a) MAC in DPEPO, (b) MAB in DPEPO.

emitter $(20 \mathrm{~nm}) / \mathrm{TmPyPb}(40 \mathrm{~nm}) / \mathrm{LiF}(1 \mathrm{~nm}) / \mathrm{Al}$. Here, ITO and $\mathrm{LiF} / \mathrm{Al}$ were respectively acted as the anode and the cathode. 1,1-Bis-(4-methylphenyl)-aminophenyl)-cyclo-hexane (TAPC) and N,N,N-tris(4-(9-carbazolyl)phenyl) amine (TCTA) were used as the hole transporting layers. $\quad$ 1,3,5-Tri(m-pyrid-3-yl-phenyl)-benzene $(\mathrm{TmPyPb})$ was used as the electron transporting layer. 9-(4-(Tert-butyl) phenyl)-3,6-bis(triphenylsilyl)-carbazole $(\mathrm{CzSi})$ was used as the exciton blocking layer. And the doping ratios were optimized as $14 \mathrm{wt} \%$ for MAC and $20 \mathrm{wt} \%$ for MAB, respectively.

The EL characteristics of two devices are shown in Fig. 7 and summarized in Table 2. The MAC-based OLED exhibits a turn-on voltage of $3.4 \mathrm{~V}$ and obtains a maximum luminance of $2,687 \mathrm{~cd} \mathrm{~m}^{-2}$ at $7.7 \mathrm{~V}$. While the MAB-based OLED realizes a turn-on voltage of $3.2 \mathrm{~V}$ and a maximum luminance of $9,518 \mathrm{~cd} \mathrm{~m}^{-2}$ at $8.1 \mathrm{~V}$, obviously better than that of MAC-based OLED. The turn-on voltage of MAB-based OLED is lower than that of MAC, which should be mainly caused by narrower energy gap and deeper LUMO energy level of MAB, making electrons easier injecting into the emitter layer. More importantly, in the device, MAC only exhibits moderate efficiencies with a maximum EQE of $12.8 \%$, a maximum $\mathrm{CE}$ of $28.4 \mathrm{~cd} \mathrm{~A}^{-1}$ and a maximum $\mathrm{PE}$ of $25.5 \mathrm{~lm} \mathrm{~W}^{-1}$, far lower than the theoretical limit of TADF-based OLEDs. While with the extended LUMO distribution, $\mathrm{MAB}$ exhibits much higher efficiencies with a maximum EQE up to $21.7 \%$ as well as a maximum CE of $56.2 \mathrm{~cd} \mathrm{~A}^{-1}$ and a maximum PE of $53.5 \mathrm{~lm} \mathrm{~W}^{-1}$ in the device. These efficiencies are consistent with the PLQYs of MAC and MAB doped in DPEPO films. And the much better performance of MAB-based OLED proves that the extended LUMO distribution could indeed benefit the exciton utilization of TADF emitters. Also consistent with the PL spectra, the EL spectra of the MAB-based OLED are slightly red-shifted compared with that of MAC-based OLED. MAB shows bluish green emission with a CIE coordinate of $(0.20,0.42)$ and a peak at $500 \mathrm{~nm}$ in the device, while MAC shows cyan emission with a CIE coordinate of $(0.19,0.34)$ and a peak at $488 \mathrm{~nm}$ in the device. Moreover, the MAB-based OLED shows a low efficiency roll-off at high brightness. The EQE of the device remains at $16.8 \%$ with a luminance of $1,000 \mathrm{~cd} \mathrm{~m}^{-2}$, and $15.2 \%$ with a luminance of $2,000 \mathrm{~cd} \mathrm{~m}^{-2}$, which should be attributed to effective RISC process and short TADF lifetime of MAB. An effective RISC process would reduce the density of triplet exciton and thereby suppress the triplet-triplet exciton annihilation at high current densities.

\section{CONCLUSION}

In conclusion, with the additional phenyl in coumarincontained plane, MAB possesses an extended LUMO distribution compared with MAC, which could reduce the electron exchange between HOMO and LUMO and stretch dipole moment of the molecule. As a result, $\mathrm{MAB}$ shows an extremely small $\Delta E_{\mathrm{ST}}$ of $0.081 \mathrm{eV}$ and a high PLQY value of $67.9 \%$. Moreover, in the device, MAB exhibits remarkable performance with a maximum EQE of $21.7 \%$, a maximum $\mathrm{CE}$ of $56.2 \mathrm{~cd} \mathrm{~A}^{-1}$ and a maximum $\mathrm{PE}$ of $53.5 \mathrm{~lm} \mathrm{~W}^{-1}$, much better than the efficiencies of MAC-based OLEDs (a maximum EQE of $12.8 \%$, a maximum $\mathrm{CE}$ of $28.4 \mathrm{~cd} \mathrm{~A}^{-1}$ and a maximum $\mathrm{PE}$ of $25.5 \mathrm{~lm} \mathrm{~W}^{-1}$ ). These results prove that extending the distribution of LUMO is a simple but effective approach 

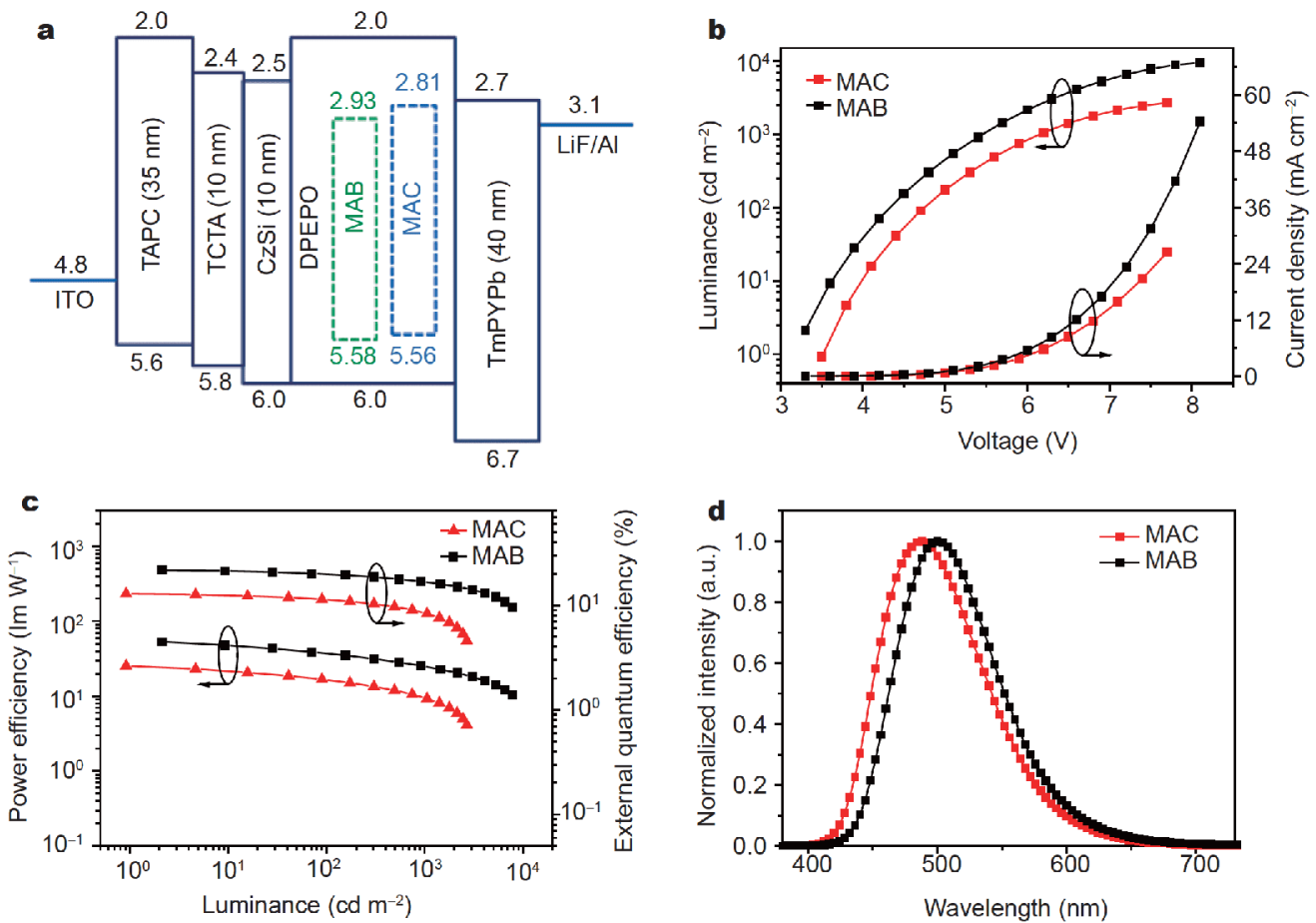

Figure 7 (a) Energy level diagrams, (b) the current density-voltage-luminance characteristics, (c) the PE-luminance characteristics and EQEluminance characteristics, and (d) the EL spectra of MAC- and MAB-based OLED devices.

Table 2 EL performance of MAC- and MAB-based OLED devices

\begin{tabular}{cccccccc}
\hline Emitters & $\begin{array}{c}V_{\mathrm{ON}} \\
(\mathrm{V})^{\mathrm{a}}\end{array}$ & $\begin{array}{c}\mathrm{CE}_{\max } \\
\left(\mathrm{cd} \mathrm{A}^{-1}\right)^{\mathrm{b}}\end{array}$ & $\begin{array}{c}\mathrm{PE}_{\max } \\
(\mathrm{lm} \mathrm{W})^{\mathrm{b}}\end{array}$ & $\begin{array}{c}\mathrm{EQE}_{\max } \\
(\%)^{\mathrm{b}}\end{array}$ & $\begin{array}{c}\mathrm{EQE}_{1000} \\
(\%)^{\mathrm{b}}\end{array}$ & $\begin{array}{c}\lambda_{\max } \\
(\mathrm{nm})\end{array}$ & $\begin{array}{c}\mathrm{CIE} \\
(x, y)^{\mathrm{c}}\end{array}$ \\
\hline MAC & 3.4 & 28.4 & 25.5 & 12.8 & 8.4 & 488 & $(0.19,0.34)$ \\
MAB & 3.2 & 56.2 & 53.5 & 21.7 & 16.8 & 500 & $(0.20,0.42)$ \\
\hline
\end{tabular}

a) $V_{\mathrm{ON}}$ : turn-on voltage recorded at $1 \mathrm{~cd} \mathrm{~m}^{-2}$; b) CE: current efficiency; PE: power efficiency; EQE: external quantum efficiency; c) obtained at $1,000 \mathrm{~cd} \mathrm{~m}^{-2}$.

to improve the efficiency of TADF emitter.

\section{Received 4 August 2018; accepted 21 September 2018;} published online 2 November 2018

1 Ma Y, Zhang $\mathrm{H}$, Shen J, et al. Electroluminescence from triplet metal-ligand charge-transfer excited state of transition metal complexes. Synth Met, 1998, 94: 245-248

2 Adachi C, Kwong RC, Djurovich P, et al. Endothermic energy transfer: A mechanism for generating very efficient high-energy phosphorescent emission in organic materials. Appl Phys Lett, 2001, 79: 2082-2084

3 Goushi K, Yoshida K, Sato K, et al. Organic light-emitting diodes employing efficient reverse intersystem crossing for triplet-tosinglet state conversion. Nat Photonics, 2012, 6: 253-258

4 Han TH, Choi MR, Woo SH, et al. Molecularly controlled interfacial layer strategy toward highly efficient simple-structured organic light-emitting diodes. Adv Mater, 2012, 24: 1487-1493

5 Li N, Oida S, Tulevski GS, et al. Efficient and bright organic lightemitting diodes on single-layer graphene electrodes. Nat Commun,
$2013,4 \cdot 2294-2300$

6 Wu H, Zhou G, Zou J, et al. Efficient polymer white-light-emitting devices for solid-state lighting. Adv Mater, 2010, 21: 4181-4184

7 Pope M, Kallmann HP, Magnante P. Electroluminescence in organic crystals. J Chem Phys, 1963, 38: 2042-2043

8 Tsutsui T, Saito S. Organic Multilayer-Dye Electroluminescent Diodes-is There any Difference with Polymer LED? Intrinsically Conducting Polymers: An Emerging Technology. Springer Netherlands, 1993, 246: 123-134

9 Rothberg LJ, Lovinger AJ. Status of and prospects for organic electroluminescence. J Mater Res, 1996, 11: 3174-3187

10 Park IS, Lee SY, Adachi C, et al. Full-color delayed fluorescence materials based on wedge-shaped phthalonitriles and dicyanopyrazines: systematic design, tunable photophysical properties, and OLED performance. Adv Funct Mater, 2016, 26: 1813-1821

11 Köhler A, Wilson JS, Friend RH. Fluorescence and phosphorescence in organic materials. Adv Mater, 2002, 14: 701

12 Yersin H, Strasser J. Triplets in metal-organic compounds. Chemical tunability of relaxation dynamics. Coord Chem Rev, 2000, 208: 331-364 
13 Baldo MA, O'Brien DF, You Y, et al. Highly efficient phosphorescent emission from organic electroluminescent devices. Nature, 1998, 395: 151-154

14 Aydemir M, Haykır G, Battal A, et al. High efficiency OLEDs based on anthracene derivatives: The impact of electron donating and withdrawing group on the performance of OLED. Org Electron, 2016, 30: 149-157

15 Zhang Q, Li B, Huang S, et al. Efficient blue organic light-emitting diodes employing thermally activated delayed fluorescence. Nat Photonics, 2014, 8: 326-332

16 Zhang Q, Tsang D, Kuwabara H, et al. Nearly $100 \%$ internal quantum efficiency in undoped electroluminescent devices employing pure organic emitters. Adv Mater, 2015, 27: 2096-2100

17 Uoyama H, Goushi K, Shizu K, et al. Highly efficient organic lightemitting diodes from delayed fluorescence. Nature, 2012, 492: 234238

18 Yang Z, Mao Z, Xie Z, et al. Recent advances in organic thermally activated delayed fluorescence materials. Chem Soc Rev, 2017, 46: 915-1016

19 Tao Y, Yuan K, Chen T, et al. Thermally activated delayed fluorescence materials towards the breakthrough of organoelectronics. Adv Mater, 2015, 26: 7931-7958

20 Zhang D, Song X, Cai M, et al. Versatile indolocarbazole-isomer derivatives as highly emissive emitters and ideal hosts for thermally activated delayed fluorescent OLEDs with alleviated efficiency rolloff. Adv Mater, 2018, 30: 1705406

21 Cai M, Zhang D, Huang T, et al. Multifunctional materials for high-performance double-layer organic light-emitting diodes: comparison of isomers with and without thermally activated delayed fluorescence. ACS Appl Mater Interfaces, 2017, 9: 1727917289

22 Wang H, Xie L, Peng Q, et al. Novel thermally activated delayed fluorescence materials-thioxanthone derivatives and their applications for highly efficient OLEDs. Adv Mater, 2014, 26: 5198-5204

23 Zhang Q, Li J, Shizu K, et al. Design of efficient thermally activated delayed fluorescence materials for pure blue organic light emitting diodes. J Am Chem Soc, 2012, 134: 14706-14709

24 Zhang Q, Kuwabara H, Potscavage Jr. WJ, et al. Anthraquinonebased intramolecular charge-transfer compounds: computational molecular design, thermally activated delayed fluorescence, and highly efficient red electroluminescence. J Am Chem Soc, 2014, 136: $18070-18081$

25 Chan CY, Cui LS, Kim JU, et al. Rational molecular design for deep-blue thermally activated delayed fluorescence emitters. Adv Funct Mater, 2018, 28: 1706023

26 Lv X, Wang H, Meng L, et al. Highly efficient inverted organic light-emitting diodes based on thermally activated delayed fluorescence. Sci China Mater, 2016, 59: 421-426

27 Hirata S, Sakai Y, Masui K, et al. Highly efficient blue electroluminescence based on thermally activated delayed fluorescence. Nat Mater, 2015, 14: 330-336

28 Endo A, Ogasawara M, Takahashi A, et al. Thermally activated delayed fluorescence from $\mathrm{Sn}^{4+}$-porphyrin complexes and their application to organic light emitting diodes-a novel mechanism for electroluminescence. Adv Mater, 2009, 21: 4802-4806

29 Im Y, Lee J Y. Recent progress of green thermally activated delayed fluorescent emitters. J Inf Display, 2017, 18: 1-17

30 Liang X, Zhang Q. Recent progress on intramolecular chargetransfer compounds as photoelectric active materials. Sci China
Mater, 2017, 60: 1093-1101

31 Xie G, Li X, Chen D, et al. Evaporation- and solution-processfeasible highly efficient thianthrene-9,9',10,10'-tetraoxide-based thermally activated delayed fluorescence emitters with reduced efficiency roll-off. Adv Mater, 2016, 28: 181-187

32 Kawasumi $\mathrm{K}, \mathrm{Wu} \mathrm{T}$, Zhu T, et al. Thermally activated delayed fluorescence materials based on homoconjugation effect of donoracceptor triptycenes. J Am Chem Soc, 2015, 137: 11908-11911

33 Ishimatsu R, Matsunami S, Kasahara $\mathrm{T}$, et al. Electrogenerated chemiluminescence of donor-acceptor molecules with thermally activated delayed fluorescence. Angew Chem Int Ed, 2014, 53: 6993-6996

34 Rajamalli P, Senthilkumar N, Gandeepan P, et al. A method for reducing the singlet-triplet energy gaps of TADF materials for improving the blue OLED efficiency. ACS Appl Mater Interfaces, 2016, 8: 27026-27034

35 Komatsu R, Sasabe H, Seino Y, et al. Light-blue thermally activated delayed fluorescent emitters realizing a high external quantum efficiency of $25 \%$ and unprecedented low drive voltages in OLEDs. J Mater Chem C, 2016, 4: 2274-2278

36 Sun JW, Baek JY, Kim KH, et al. Thermally activated delayed fluorescence from azasiline based intramolecular charge-transfer emitter (DTPDDA) and a highly efficient blue light emitting diode. Chem Mater, 2015, 27: 6675-6681

37 Rajamalli P, Senthilkumar N, Gandeepan P, et al. A new molecular design based on thermally activated delayed fluorescence for highly efficient organic light emitting diodes. J Am Chem Soc, 2015, 138: 628-634

38 Jankus V, Data P, Graves D, et al. Highly efficient TADF OLEDs: How the emitter-host interaction controls both the excited state species and electrical properties of the devices to achieve near $100 \%$ triplet harvesting and high efficiency. Adv Funct Mater, 2015, 24: 6178-6186

39 Liu W, Chen JX, Zheng CJ, et al. Novel strategy to develop exciplex emitters for high-performance OLEDs by employing thermally activated delayed fluorescence materials. Adv Funct Mater, 2016, 26: $2002-2008$

40 Chen JX, Liu W, Zheng CJ, et al. Coumarin-based thermally activated delayed fluorescence emitters with high external quantum efficiency and low efficiency roll-off in the devices. ACS Appl Mater Interfaces, 2017, 9: 8848-8854

Acknowledgements This work was supported by the National Natural Science Foundation of China (51773029, 51533005 and 51373190), the National Key Research \& Development Program of China (2016YFB0401002), Collaborative Innovation Center of Suzhou Nano Science \& Technology, the Priority Academic Program Development of Jiangsu Higher Education Institutions (PAPD), and the 111 Project and Qing Lan Project, China.

Author contributions Zheng CJ, Wang $\mathrm{K}$ and Zhang XH designed the whole work; Ke K and Chen JX synthesized the organic compounds; Ke K and Shi YZ characterized the physical properties of compounds; Zhang M, Lin $\mathrm{H}$ and Tao SL fabricated and optimized the devices; Ke K wrote the paper with support from Zheng CJ, Wang K and Zhang XH. All authors contributed to the general discussion.

Conflict of interest The authors declare no conflict of interest. 


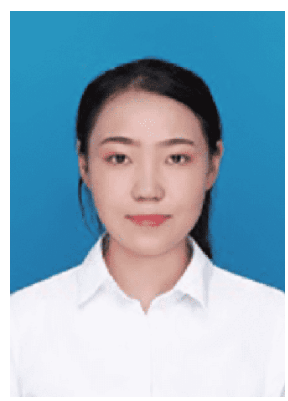

Ke Ke is a master student of the organic optoelectronic laboratory at the University of Electronic Science and Technology of China. Her research is focused on the optoelectronic materials and devices, mainly in the design, synthesis, manufacture and characterization of thermally activated delayed fluorescent materials for OLED.
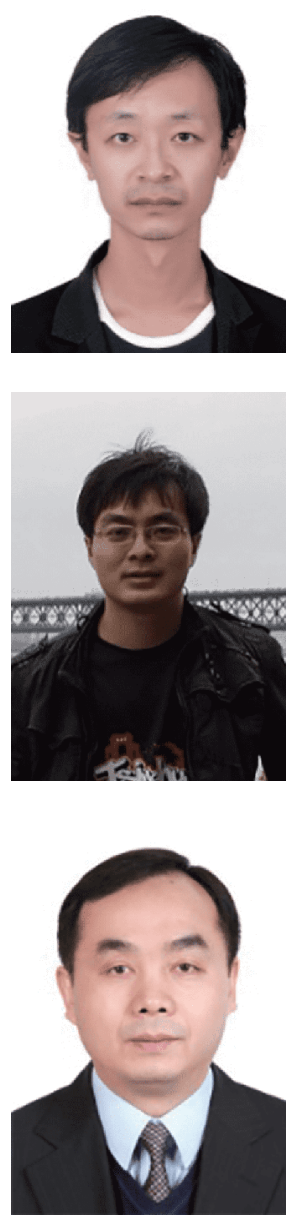

Kai Wang received BSc degree from the Department of Materials Science and Engineering, Beijing University of Aeronautics and Astronautics in 2012, and received PhD degree from the Technical Institute of Physics and Chemistry of Chinese Academy of Sciences in 2017. He became a postdoctoral fellow in 2017 in Soochow University. His research interest focuses on materials developments and device fabrications for OLEDs.

Cai-Jun Zheng received BSc degree from the Department of Chemistry, Tsinghua University in 2005, and PhD degree from the Technical Institute of Physics and Chemistry, Chinese Academy of Sciences in 2010. He joined the University of Electronic Science and Technology of China as a professor in 2016. His current research interest mainly focuses on the organic optoelectronic materials and devices.
Xiao-Hong Zhang received BSc and MSc degrees from the Department of Materials Science and Engineering, Beijing University of Aeronautics and Astronautics in 1989 and 1992, and received PhD degree from the Department of Chemical Engineering and Materials Science, Beijing University of Technology in 1996. He joined Soochow University as a professor in 2013. His current research interest mainly focuses on organic optoelectronic materials and devices and semiconductor nano-materials and devices.

\title{
通过扩展LUMO分布提高热激活延迟苂光材料的性能
}

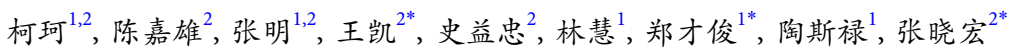

摘要 为了进一步提高热激活延迟苂光(TADF)发射体的性能, 我们基于之前报道的 TADF材料MAC, 设计并合成了优化的化合物MAB. 通 过在香豆素平面中加入苯基, 扩展了 $\mathrm{MAB}$ 的最低未占据分子轨道(LUMO)的分布. 与MAC相比, MAB减少了前沿分子轨道的电子交换并 且延展了分子偶极矩, 从而提升了材料性能. 基于MAB的有机发光二极管(OLED)的最大外量子效率(EQE)为 $21.7 \%$, 远远高于采用MAC作 为发光材料的OLED器件 $12.8 \%$ 的最大 EQE. 我们的工作证明, 扩展LUMO的分布是提高TADF材料性能的一种简单而有效的方法. 